\title{
Graph Theory as a Tool for teaching Mathematical Processes
}

\author{
Nasim Asghari, Ahmad Shahvarani, Ahmad Reza Haghighi \\ Department of Mathematics ,Islamic Azad University, Central Tehran Branch, Iran \\ Department of Mathematics, Islamic Azad University, Science and Research Branch, Iran \\ Department of Mathematics ,Urmia University of Technology, Iran
}

\begin{abstract}
Graph theory is mathematics strands. It is a interesting subject matter. Our claim is that this subject can serve as a tool for learning mathematical processes .Notional council of teachers on mathematics of America (NCTM) proposed five standards that students should learn in K-12. In this paper we showed how can use Graph theory to teach three standards of NCTM. It is a suitable context to teach problem solving and there is good connection between Graph theory and other science. Finally it can be used for representing models and physical situations.
\end{abstract}

\section{Introduction}

The $3^{\text {rd }}$ Millennium of A.D., has brought the new challenges for educational systems "Pre-knowledge requirement" for school children the $21^{\text {st }}$ century is very different from 3 decades before. Great social changes, improvement of informational sources and new achievements of researches about children's learning, requires systematic planning of mathematics and science curriculum which responses the social needs of children. We should bring about changes which include these new topics to enable us for the achievement of the aims in the new curriculum. Discrete Mathematics and Graph Theory introduced in the standards intended by the American National Council of teachers included in the school Mathematics Curriculum in 2000.

Iran tried to include the subject in the Mathematics Curriculum with a limited scale. In this article I'm going to show the importance of including the Graph Theory in the programs in schools in different levels. Principles and standards of school-Math claim that: "Discrete Mathematics and Graph should be a integral part of the entire content of the School-Math" [8].

DIMACS, the center of Discrete Math and Computer Science in its conference Manifestation in 1992 asserts that: "During 30 years, the discrete Mathematics has progressed rapidly and has converted to an important Math-field. Discrete Mathematics, as a major language of science is very vital for decisionmaking for the life or job for any citizen" [3].
On one hand, the progress of Discrete-Math and Graph and its application in various sciences such as 'Chemistry, Electrical fields, research in operations, computer planning, encoding and social sciences, and the other hand, the declared aims of Math-education by NCTM shows that it is necessary to include the Graph

\section{Analysis}

Five standards of the NCTM cover the importance of Graph Theory. These standards are: [10]
1. Problem solving
2. Communication
3. Reasoning
4. Connection
5. Representation

It seems that teaching the Graph Theory can help the students to reach to three of five goals mentioned above:

\subsection{Connection standard}

The connection standards claim states that," the Instructional programs from Pre-kindergarten through k-12 should enable all students to recognize and use connections among mathematical ideas and understand how these ideas connect to each other and build on one another to produce a coherent whole" [8].

The following activity has given a new idea such as peddler and makes clear the relation and coherence between graph and topics Matrix, transformation, Reflection and rotation. Here, I investigate properties of the qualities of Geometrical shapes which are constructed drawing Hamilton circuits which are created by joining the vertices of a regular Polygon. Suppose we give the students some sheets which contain orderly 4 cities, 5 cities and 6 cities which are situated on the vertices of one square, a pentagon and a hexagon and polygon marked by $0,1,2,3,4$ and 5 numbers. So we ask them to draw the Hamilton circuits and that which has zero as its beginning and end [6].

They would find out that each way corresponding to transformation are combined 1,2,3,4, and 5 numbers. If we show the number of cities by " $n$ ", in that case the 
number of Hamilton circuits are equal to $(n-1)$ ! Since some of them are obtained by others through reflection or rotation.

Then, we asked the students to draw a table to compare the numbers of the symmetric lines with the numbers cases in each square, pentagon and hexagon (table 1). Then, the students will observe that when the numbers of the symmetric lines aren't equal to zero (0), the numbers of shapes are equal to $(n / s)$, where (n) is the numbers of cities and (s) is the numbers of symmetric lines.

Table 1. The relationship between the number of cities, the number of symmetric lines and the number of cases

\begin{tabular}{|l|l|l|l|l|}
\hline $\begin{array}{l}\text { No. of } \\
\text { polygon }\end{array}$ & $\begin{array}{l}\text { No. of } \\
\text { shape }\end{array}$ & $\begin{array}{l}\text { No. of } \\
\text { cities }\end{array}$ & $\begin{array}{l}\text { No. of } \\
\text { symmetric } \\
\text { lines }\end{array}$ & $\begin{array}{l}\text { No. of } \\
\text { cases }\end{array}$ \\
\hline Square & 1 & 4 & 4 & 1 \\
& 2 & 4 & 2 & 2 \\
\hline Pentagon & 1 & 5 & 5 & 1 \\
& 2 & 5 & 5 & 1 \\
& 3 & 5 & 1 & 5 \\
& 4 & 5 & 1 & 5 \\
\hline Hexagon & 1 & 6 & 6 & 1 \\
& 2 & 6 & 3 & 2 \\
& 3 & 6 & 2 & 3 \\
& 4 & 6 & 2 & 3 \\
& 5 & 6 & 2 & 3 \\
& 6 & 6 & 1 & 6 \\
& 7 & 6 & 1 & 6 \\
& 8 & 6 & 1 & 6 \\
& 9 & 6 & 1 & 6 \\
& 10 & 6 & 1 & 6 \\
& 11 & 6 & 0 & 6 \\
& 12 & 6 & 0 & 12 \\
\hline
\end{tabular}

Also, it's possible to reinforce the mathematical relations by expressing the relations of the Graphs and reflective relations, symmetrical, transitional and equivalence relations and besides the relations between two-sector graphs and functions. The inclusion and exclusion principles and the relation between pigeonhole principle and Graph are being reinforced by solving problems in Graph Theory. Also the students find that there is a relation between determinants and the sets of vertex of Graphs.

a) For example, there is a relation between minor and matrix $\mathrm{M}$ as follows [1].

$$
\begin{gathered}
M_{31}=\left[\begin{array}{cccc}
0 & 1 / 3 & 2 & 3 \\
0 & 1 & 1 / 2 & 0 \\
1 & 0 & 0 & 0 \\
0 & 3 & 1 & 0
\end{array}\right] \\
M=\left[\begin{array}{cccc}
2 & 1 / 3 & 2 & 3 \\
1 / 2 & 1 & 1 / 2 & 0 \\
3 & 0 & 0 & 4 \\
0 & 3 & 1 & 0
\end{array}\right]
\end{gathered}
$$

And the corresponding graph is displayed in Figure 1.
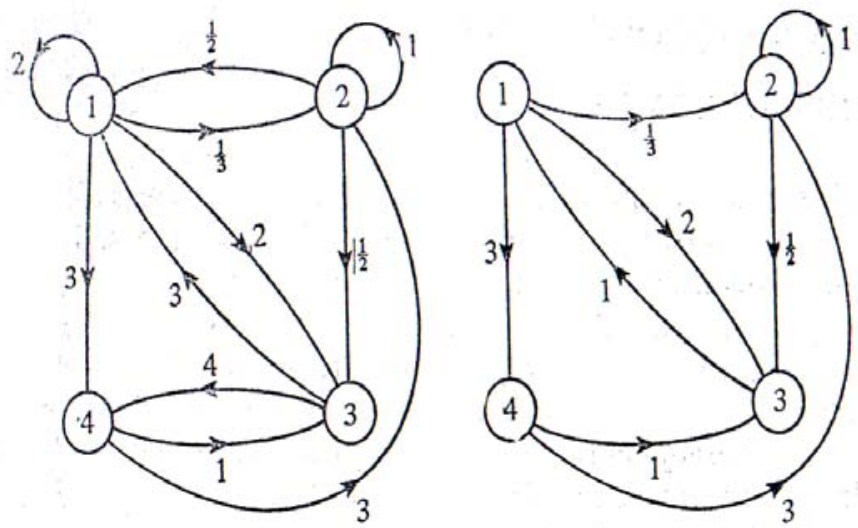

Figure 1. Graph of the relation between minor and matrix $\mathrm{M}$.

b) We can give a graphical description of theorem $M(\operatorname{adj} M / \operatorname{det} M)=I$ by the definition given in (a). [5]

\subsection{Representation Standard}

The standard of representation assert that the "Instructional programs from pre-kindergarten through grade 12 should enable all students so create and use representations to organize, record , and communicate mathematical ideas and use representations to model and interpret physical, social, and mathematical phenomena" [8]. Graph coloring also is a subject emphasized by NCTM standards. 
Have you ever waited in a traffic light? Have you thought how traffic lights work? Who turns-on the green-light simultaneously? How many chronological periods do we need for traffic lights? Or, have you ever thought about how the final exam in a course should be scheduled such that there is not any contact between exams? These types of problems can be modeled by graph and using graph coloring.

In another problem, suppose that 17 persons have decided to go to a trip and they have decided to send a letter to 5 other friends before going. Is it possible for any one to send letters to 5 persons and receive letter from the same 5 person? It is possible to model the problem and find answer by using as Graph. We show the persons by the vertices of the Graph and sending and delivering of the letters by edge. The Graph of the problem will be as follows (see Figure 2).

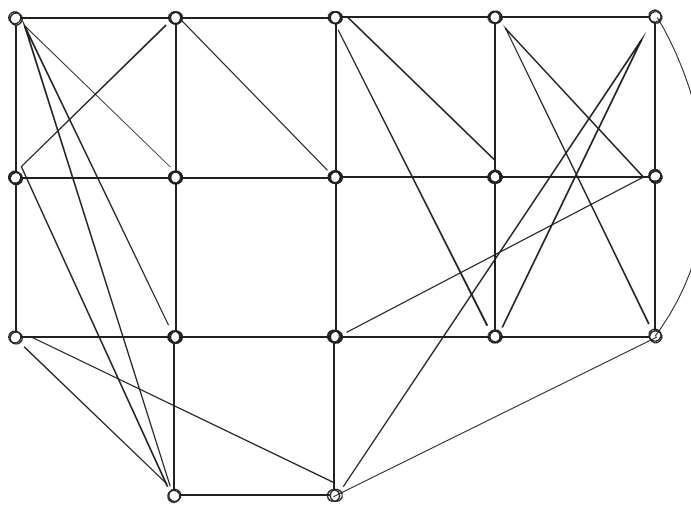

Figure 2. Graph of the relation between 17 persons and their sending letter

\subsection{Graph as a suitable field for standard of problem solving}

Problem solving standards assert that "Instructional programs from pre-kindergarten through grade 12 should enable all students so build new mathematical knowledge through problem solving and apply and adapt a variety of appropriate strategies to solve problems"[8].

The difficulty in defining the "problem" is related to how to solve the problem. The problem is not the innate property of Mathematic, but it is a (rational concept). The very affairs which need so many attempts in the behalf students are normal practices for others and solving those problems is only remembering for a mathematician. This concept is something which Polya has called "problem" [2].

Schoenfeld believes that sources, controls, heuristic and beliefs systems are four major factors which are effective in problem-solving. The sources are foundations on which problem-solving is based.

A successful performance depends on relevant knowledge concerning on the given problem. Heuristic are some strategies which good problem-solvers apply them during problem-solving. Schoenfeld emphasizes that these heuristics should be taught to students. To guess if one heuristic helps or does not help to solve the problem depends to control and at last, belief system is effective on students to persist in solving problem or putting it away. When a student believes that a problem should be solved in 10 minutes, he/she soon put the problem away automatically [10].

Graph is a relevant subject for giving the students awareness that doing Mathematics is a something more than an algorithm. It is an interaction between mind and emotion. Disappointment and failing is common in problem-solving process. To solve the problems by using Graph modeling the students would be capable of trying different methods. Graph provides them a set of methods for modeling problems.

Euler has asserted and solved the" seven bridge problem of Konigsberg”, and I have tried to analyze the process of problem-solving here. The problem is as follows: In Konigsberg city, there is an island which has seven bridges built on the two branches of the river which connect it to the city. Is it possible to find a path which passes all bridges and only once? Euler, first designed the problem simply and frankly. Then, he is goes on to find a better heuristic by investigation. He puts away the difficult and inapplicable ideas. He uses A, B... letters for showing areas and show $A B$ passing from bridge A to bridge B [11].

Consequently, for finding a path which can pass from seven bridges, it is necessary to show it with 8 letters. For finding this combination of letters he tries to dominate the research activity.

Then he generalizes it as follows: he asserts that since can enter in and exist from the Island (A) by five bridges, so we can provide combination, in which the letter $\mathrm{A}$ is repeated three times and the letter B, D and $\mathrm{C}$ two times in it. But, it is not possible to have nine letters in an eight-letters combination. Consequently, passing from seven bridges as asked in the problem is not possible. After solving the problem he continues the work and makes a generalization and presents the first theorem of Graph Theory. (The numbers of odd vertexes of any graph is even).

\section{Conclusion}

Generally speaking, the graph theory is a rich source in problem-solving. We can taste so many different strategies. It is possible to make the students to think creatively. The student will construct a collection of 
ideas by making relation between different Mathematical- topics. The student also, will solve the problems by Graph modeling and show them graphically.

As a result, we can help the students to reach the goals in learning Mathematics. It is clear that including the Graphs in all levels of school Mathematics is necessary and relevant as a problem solving frame not a drill practice.

\section{References}

[1] Biggs, Norman L., E. K. Lloyd, and Robin J. Wilson. Graph Theory: 1736- 1936. Oxford: Clarendon Press, 1976.

[2] Billstein R., Libeskind, S.Lott J., A Problem Solving Approach to Mathematics for Elementary School Teachers, (2nd Ed.) Benjamin Cummings Publish. Co.1984.

[3] Debellis.V and Rosenstein, j .Discrete Mathematics in Primary and Secondary Schools in the United States .ZDM. (NC)(USA).

[4] Dunham, William. Euler: The Master of Us All. Washington: The Mathematical Association of America, 1999.

[5] Girimaldi, R.P, Discrete and Combinatorial Mathematics, and Applied Introduction, Addison- Wesley Publishing Company, 1989.

[6] Hopkins, Brian, and Robin Wilson. The Truth about Konigsberg. College Mathematics Journal (2004), 35, 198207.

[7]Janowski,A. Integrating mathematics strands. Mathematics Teachers, Vol.90, No.7, October 1997.

[8] National Council of teachers of Mathematics - Principles and Standards for School Mathematics (2000).

[9] Schoenfeld, Alan H. (1985).Mathematical Problem Solving. Academic Press, INC.

[10] Schonfield, A. Training of Problem Solving Art .Journal the Skeptic Vol. 16No.1, 1996

[11] Teo Paulette, Leonard Euler's. Solution to the Konigsberg Bridge Problem Journal, the Mathematical Association of America, Vol.18, 247-252, 2004. 